\title{
Greater Stress Level Fluctuation from onset of Coronavirus Pandemic for Lower Income Earners
}

\author{
Claire Padilla ${ }^{1}$ and Elaine Pan ${ }^{1}$ \\ ${ }^{1}$ The Chapin School, New York, New York, USA
}

\begin{abstract}
$\underline{\text { ABSTRACT }}$
Natural disasters, mental illnesses, injuries, and crime are all known factors that lead to stress (Casarella 2020). People were in various levels of confinement due to Coronavirus all over the world, leading to job loss and inability to finance basic living expenses. This study evaluated the relationship between stress and income by surveying different socioeconomic groups. All the participants took a PSS (Perceived Stress Scale) and SRRS (Social Readjustment Rating Scale) test that included questions about race, age range, income range, and the number of times they think about Coronavirus each day. Dr. Cohen's 2009 PSS score samples of the American population were used as a baseline measurement for the pre-Coronavirus stress score levels. The stress level fluctuation was calculated by subtracting participants' survey scores from Cohen's scores to determine the overall stress level change. A p-value of 0.00000001196 for the lower-income group $(<\$ 30 \mathrm{k} / \mathrm{yr})$ and a p-value of 0.01214 for the higher income group $(>\$ 91 \mathrm{k} / \mathrm{yr}$ ) was obtained using the independent-t-test. These $\mathrm{p}$-values supported the alternative hypothesis proposed in this study that there is a more significant change in the stress levels spanning the onset and duration of the Coronavirus pandemic in members of a lower socioeconomic bracket $(<\$ 30,000 / \mathrm{yr})$ than of people in a higher income bracket $(>\$ 91,000 / \mathrm{yr})$. The results revealed that the PSS score of the 65 years and older group had increased the most and no significant difference in stress scores between racial groups. Additionally, people who think about Coronavirus more frequently have higher PSS scores.
\end{abstract}

\section{Introduction}

The body's response to any change that needs an adjustment or action is called stress. The body tends to respond to this change with a mental, physical, or emotional response (Cleveland Clinic 2015). Stress can be caused by many factors, including bodily injuries, mental illnesses, national disasters, natural disasters, and crime (Casarella 2020). While stress is inevitable, it can be healthy and may help people complete tasks more efficiently (Ulifeline 2020). However, too much stress can be hazardous and can also lead to a multitude of unhealthy disorders such as anxiety, depression, high blood pressure, personality disorder, heart attacks, and stroke (WebMD 2019).

Currently, all over the world, people are experiencing confinement and quarantine for the first time due to Coronavirus or COVID-19. The recent quarantine has caused a lot of change across the globe, such as widespread unemployment. Unemployment in the United States has been increasing astronomically due to Coronavirus. In the United States, the unemployment rate has risen from 1.4 million to 7.1 million in March (bls.gov 2020). According to ET Bureau (2017), job loss can have a tremendous psychological impact on all the individuals of a family.

People are also very concerned about being infected with the COVID-19 virus due to its very high contagiousness and unclear routes of spread, which has been discussed often in the media (Taylor 2020). About half of the American population reports that the coronavirus pandemic has been afflicting their mental health. A federal hotline has experienced a 1,000\%increase in people that are emotionally distressed from April last year (Wan 2020). To educate people and decrease spread, public health officials have discussed warnings and possible projections, including high mortality rates of up to potentially millions of people repeatedly via multiple media outlets. In addition to fear of catching the virus and of death, there has been an adverse reaction to confinement. One early reaction from 
people included purchasing large amounts of food, water, and toilet paper due to the Coronavirus pandemic (Taylor 2020). There have been shortages in stores of face masks, as well due to manufacturing issues and even hoarding of masks (Taylor 2020). Many people on the front lines of the disease were unable to receive the proper personal protective equipment (PPE), such as doctors, nurses, and couriers. All of these new changes due to COVID-19, caused more fear of infection, loss of income, loss of shelter, and loss of food and were bound to compound stress.

There are minimal published studies on the COVID-19 virus due to its recent discovery in December 2019. However, its spread has led to a worldwide Coronavirus pandemic that has infected people across various races and socioeconomic statuses. Many people began applying for unemployment insurance. According to the New York Times (2020), the United States has 20 million unemployment claims, a statistic that has not been seen since the Great Depression of the 1920s. This experiment compares the change of stress levels and life change index between people earning a lower income and people earning higher income during the Coronavirus pandemic. It is anticipated that people in a lower income bracket, which is defined by the HHS 2020 guidelines in the US as \$26,200 and below for a family of four, have experienced more stress and a higher life change index due to the Coronavirus as compared to families of the middle and upper class (ASPE 2020). Furthermore, this study explores the relationship between stress and race as there is a published correlation between race and income. $63 \%$ of immigrants that are low income are Hispanic. Of native-born Americans, black people make up 53\% of low-income earners. White Americans have the lowest percentages of people with low income in both the immigrant and native categories (Simms and Fortuny et al. 2009). In Chicago, $45 \%$ of the Coronavirus cases are African Americans. In Albany, Georgia, $81 \%$ of the African American population that contracted the Coronavirus have died (Taylor 2020). African Americans have the highest probability of dying from the Coronavirus due to a lack of investment in healthcare in African American communities (Wolfe 2020).

The alternative hypothesis for the experiment was: There is a greater difference in the stress levels pre and during the Coronavirus pandemic of those earning a lower income $(<\$ 30,000 / \mathrm{yr})$ than of people earning a higher income ( $>\$ 91,000 / y r)$. The null hypothesis was: There is not a significant difference in the stress levels events pre and during the Coronavirus pandemic of those earning a lower income $(<\$ 30,000 / \mathrm{yr})$ than of people earning a higher salary $(>\$ 91,000 / \mathrm{yr})$.

\section{Materials and Methods}

The Perceived Stress Scale (PSS) test was administered as a survey to the American population to see whether average stress levels have increased more in low-income communities than in affluent ones. The study collected data on demographics, including race and age, to evaluate for other possible factors that could affect stress levels aside from the independent variable for the experiment, which was different income levels. The dependent variables were different stress levels as determined by PSS and SRRS (Social Readjustment Rating Scale) scores. Only the PSS scores were used to determine the p-values. The relationship between race and income levels was also assessed to evaluate if there is also a correlation between those two variables. Stress levels were calculated using the standard PSS test and SRRS test to elicit the participant's score (Figures 1 and 2). In addition, another survey question was, "How often do you think about the Coronavirus daily." Participants were then categorized based on whether they thought about the Coronavirus more than five times a day or less than five times a day. This allowed a comparison to be made between the stress levels of the people who thought about the Coronavirus more frequently versus those who thought about it less. Demographic information, including a participant's age ranges and race, were also obtained. Participants' age ranges were divided into the following groups: 18-24 years, 25-34 years, 35-44 years, 45-54 years, 55-64 years, and 65 years and above (Figure 3). The participants were also asked to select which race they identified with. The options were: African American, Asian, Hispanic/Latino, Caucasian, Native American, and other (Figure 2). Participants were allowed to select more than one option. Respondents were also asked whether they resided in the United States of America as only participants who lived in the US were included in the data pool. In order to protect participants' identities, this survey remained anonymous. 
The survey was delivered through the platform "findparticipants.com" in order to minimize bias. The goal was to recruit at least 250 participants to increase the diversity of participants. In order to reach that goal, a sample of convenience was also used. The combination of the two sampling techniques resulted in a total sample size of 300 respondents. Participants' results were categorized by race, age, the number of times they thought about the Coronavirus, and income. The average scores in these categories were used to find the mean PSS score in each of the categories. These calculations were then compared to Dr. Cohen's PSS scores from his 2009 study. After the data was organized, it was determined that it followed a normal distribution, and the independent-t-test was performed. The data was analyzed and organized on Google Sheets (Figure 4).

\section{Results}

The t-test revealed a greater increase in stress for people earning a lower income (less than $\$ 30,000 / y r$ ) compared to people earning a higher salary ( $\$ 91,000$ and more/yr). The average PSS score of participants with a salary above $\$ 91,000 / \mathrm{yr}(\mathrm{n}=135)$ was 18.56 . The average PSS score for people with a salary of less than $\$ 30,000 / \mathrm{yr}(\mathrm{n}=41)$ was 26.395 (Figure 1). There was an 8.6 difference between average PSS score for people with an income of $<\$ 30 \mathrm{k} / \mathrm{yr}$ in 2009 (Dr. Cohen 2009) and in 2020; however, there was a 3.8 difference between average PSS score for people with an income of $>\$ 91 \mathrm{k} / \mathrm{yr}$ in 2009 (Dr. Cohen 2009) and 2020. The p-values verifying the results are 0.00000001196 $(<\$ 30,000 / \mathrm{yr})$ and $0.012(\$ 91,000+/ \mathrm{yr})$. The SRRS scores also showed that during the Coronavirus pandemic, people with a salary of less than $\$ 30,000$ per annum experienced more stress-inducing events. The average SRRS score for a person earning an income of less than $\$ 30,000$ per annum was 238.4 , while people earning a salary of above $\$ 91,000$ per annum had an SRRS score of 158.42 (Figure 2).

The descriptive statistics from this study revealed that African American/Black people $(n=135)$ had the greatest increase in stress due to the Coronavirus based on PSS scores. They had a 4.178 increase in points compared to the other races whose scores all experienced an increase of fewer than 3.5 points (Figure 3). The Caucasian group $(\mathrm{n}=84)$ had the highest SRRS score of 177.35 , while the lowest SRRS average was Hispanic/Latino group ( $\mathrm{n}=59)$ with a score of 171.378 (Figure 5).

The aged 65 years and older group $(n=10)$ had the highest increase in the PSS score from Dr. Cohen's 2009 results. The 65 years and older group's score increased by 12.36 points. This increased more than any other age group; all the other groups had an increase from one to three points., with the exception of the 18-25 years age group $(\mathrm{n}=22)$, who also experienced a larger increase of 9.4 points (Figure 6). The SRRS scores for the 65 years and older group were also the highest (244.1) with the 18-25 years group following close behind (206.1). This data matches the dramatic increase in PSS scores from 2009.

Participants who thought about the Coronavirus less than five times a day $(\mathrm{n}=82)$ had an average PSS score of 16.72. Their average was lower than people who thought about the Coronavirus 5 times or more a day $(\mathrm{n}=212)$, whose average was 20.825 (Figure 8). This pattern was also seen in SRRS scores. People who thought about the Coronavirus 5 or more times a day had an SRRS score of 177.514, while people who thought about the Coronavirus less than five times a day had an SRRS score of 175.41 (Figure 9). People who thought about the Coronavirus more than five times a day, have been experiencing more stressful life events due to the Coronavirus and have higher PSS scores.

\section{Discussion}

It can be concluded that there is a significantly greater increase in the stress levels spanning the onset and duration of the Coronavirus pandemic for those earning a lower income $(<\$ 30,000 / \mathrm{yr})$ than for those earning a higher income $(>\$ 91,000 / \mathrm{yr})$ with a confidence level of $98 \%$ and $\mathrm{p}$ values of $.00000001196(<\$ 30,000 / \mathrm{yr})$ and $0.012(>\$ 91,000 / \mathrm{yr})$. This means that there are statistically significant differences in the increase in PSS scores between people earning an 
income of less than $\$ 30,000 / \mathrm{yr}$ compared to a person with an income of greater than $\$ 91,000 / \mathrm{yr}$. When comparing descriptive statistics, one can see that the differences in averages between the scores from Dr.Cohen's 2009 research and the scores from this study for the $\$ 30,000 / \mathrm{yr}$ and lower groups were 8.6 (Figure 1 ). This difference is more than one and a half times as great as the stress differential for people who earn an income of greater than $\$ 91,000 / y r$.

This significant increase in difference is likely due to the number of stressful situations people making less than $\$ 30,000$ a year were experiencing. According to the SRRS scores collected in the surveys, people earning an income of less than $\$ 30,000$ per annum, were experiencing more stressful life events due to Coronavirus pandemic, such as change in responsibilities at work and change in financial state. This group had an average score of 238.421, while the group earning $\$ 91,000 / \mathrm{yr}$ or more had an average score of 159.64 (Figure 2). In April of 2020, half of the lower-income individuals reported wage or job loss due to the Coronavirus pandemic (Parker and others 2020). This may account for a lot of the stress that low-income individuals were experiencing since job loss is one of the most stressful life-altering events (Mckay 2020). A few cities, like Philadelphia and New York City, were also experiencing Coronavirus testing inequality (Lubrano 2020). People with higher incomes were experiencing faster covid antibody testing rates than low-income individuals, which may have contributed to the stress increase in lower-income individuals.

According to their PSS score, people over the age of 65 years also had the highest increase in stress when comparing the different age groups. The average SRRS score for the participants who were 65 yrs and older was 297.89. The 65 and older range also had the highest SRRS scores compared to the other age groups (Figure 7). Their stress score was 23.4 (Figure 6). This pattern is very different from Dr. Cohen's 2009 study, where the 65 and older age group had the lowest stress rates. The health-related nature of the stressor can explain this difference. Older people are more susceptible to the Coronavirus and have the highest death rates among the different age groups (Britt 2020). According to immune biologist Janko Nikolich-Zurich, "Older people are not as good at reacting to microorganisms they have not encountered before" (Begley 2020). This may account for a large number of deaths and stress in the 65 and older range. Natural disasters such as Coronavirus affect a wide range of people, especially the elderly, lowincome communities, and children (Sheikh, 2020). This explains some of the patterns in the data collected. The 65 years and older range had the highest PSS and SRRS scores followed closely by the 18-25 group (Figures 6 and 7). According to the American Psychological Association (APA) (2012), Millennials struggle the most with managing stress and stressful situations. The APA concluded that this is because it is harder to live a healthy lifestyle as a millennial in the United States. Millennials are more likely to engage in unhealthy stress-relieving methods like drugs and drinking (APA 2012). This may account for the increase that the 18-25 group has experienced when handing stress that may come from the coronavirus pandemic. According to the APA, the Mature age group (aged 65 and older) have the lowest stress rates. The APA predicts this is because most seniors are retired, but experience more health concerns that affect their family. The data that the APA collected is very different from the data collected in this study. This can be due to the low amount of Matures that took the survey that was used for this experiment $(\mathrm{n}=10)$. This difference also might be due to the participants who took this survey may be experiencing more risk to the Coronavirus due to their increased susceptibility to a deadly virus (APA 2012).

The results that were received about race were very different than expected or predicted. It was expected that the black and Hispanic category would get a higher score than the white category. According to the National Institutes of Health, African Americans and Latino people have, on average more chronic stress, higher risk for depression, and more unhealthy behaviors than their White counterparts (Newton 2018). Black people are also up to 33\% of those who have been hospitalized with the Coronavirus, while they represent only $13 \%$ of the American population (Aubrey 2020). According to Dr. Cohen's data from 2009, there was a small difference of .2 in PSS scores between the racial demographics of Black and White. When comparing the average PSS score in the different racial categories of Dr. Cohen's 2009 study, one can see that the difference between the Hispanic and white group was 2 points. The Hispanic category had the highest PSS score. Based on the data received from the surveys, the Caucasian group had a higher SRRS score than the other groups of color. The data collected in this experiment is most similar to Dr. Cohen's results. After looking at the individual results for each category on the race's SRRS test, it can be determined that the highest 
score, white people, is not statistically significant (Figure 5). All the racial groups have been equally affected by the Coronavirus based on the SRRS test. The African American's participant's SRRS average was 172.1 while the Hispanic/Latino average was 171. The average White participant's SRRS score was 177(Figure 5). Dr. Assari (2016) hypothesizes that Black Americans might be more resilient to stress than white Americans. Many people of color, including black people have been susceptible to minority stress. Minority stress is the anxiety that comes from experiencing everyday acts of discrimination. Many minorities have developed a strong resilience to help cope with the added stress experiencing daily acts of discrimination (Reynolds 2018). This may explain why African Americans have similar stress levels compared to White Americans. African Americans may be experiencing more loads of stress due to minority stress, but developed a resilience for this stress along with the stress of being an active member in this society. This may account for the very similar PSS scores that Dr. Cohen and this experiment experienced between these racial categories.

The participants who thought about the Coronavirus less than five times a day had a lower PSS score of 16.66, while those who thought about the Coronavirus 5 or more times had a higher score of 20.8 (Figure 8). Studies show that a stream of thoughts or jumbled thoughts can cause stress and this may account for the increased stress scores that people who think about the Coronavirus 5 or more times a day experience (Mayo Clinic 2020). People who ruminate or overthink certain ideas or topics tend to hyperbolize their situations and add more stress to their situations. Overthinking, rumination, along with pressure can lead to more stress (CCL 2020).

For future research, instead of comparing research to Dr. Cohen's PSS results in 2009, the data collected can be compared to the APA's research in 2012. In place of the PSS test, the 10-point test created by the same Dr. Cohen, would be used to determine participants' stress levels. The 10-point test is very similar to the PSS test and both are considered accurate. The 10-point test would be used to better compare the data retrieved from the survey to APA's results because the APA used the 10-point test to analyze their data. If the APA's data was used, the increases in stress could be compared throughout different cities like New York and Los Angeles. Furthermore, this more recent data would serve as a better comparison because it was taken after social media, such as Instagram, became very popular. Due to the addictive nature of social media, people can get hooked relatively quickly. As soon as one logs in, it is an addition of stress because one feels the need to be constantly updated with the present world. Social media also decreases sleep quality and isolates people (Linetti 2019). Professor Tarafdar states that people are increasing their stress levels and falling into addictive patterns; people are using their stressor (social media) as a flawed coping mechanism (Hillard 2019). This may account for the increase in all stress categories between PSS scores in 2009 and the data collected in this experiment. A figure showing the differences in increase between each income range in PSS score.

\section{Figures}

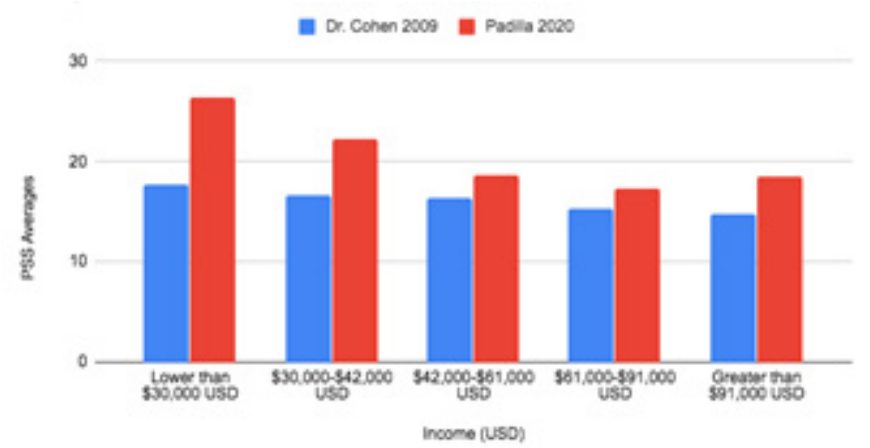

Figure 1. A figure showing the differences in increase between each income range in PSS score. 


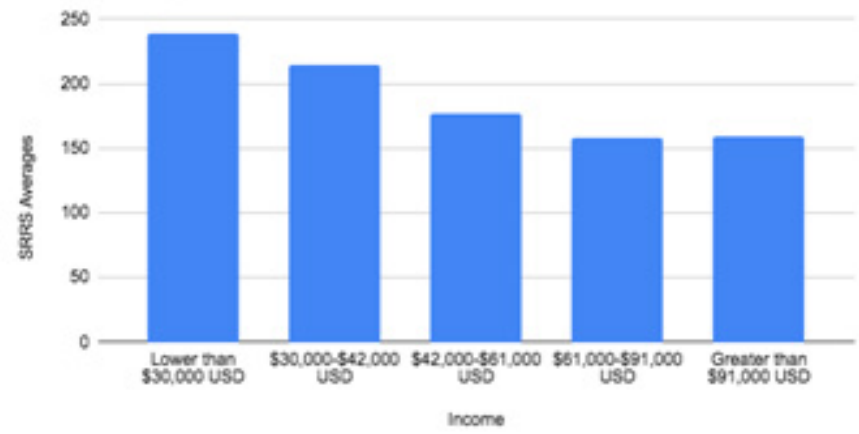

Figure 2. A figure showing the differences in SRRS scores between the different income ranges.

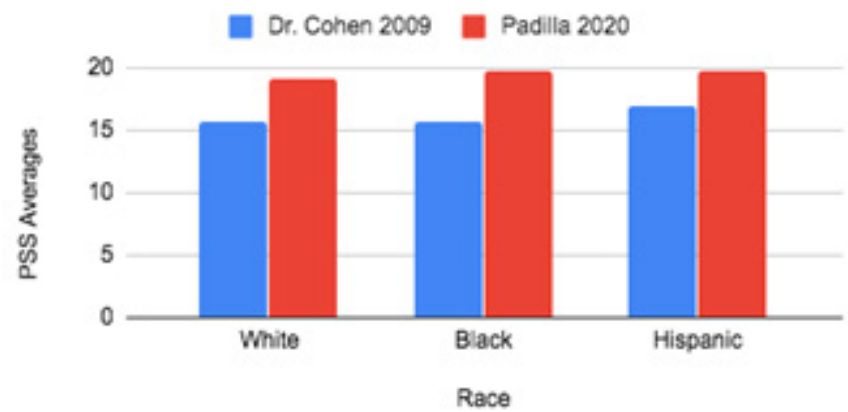

Figure 3. A figure showing the different increases in PSS score in the different Races.

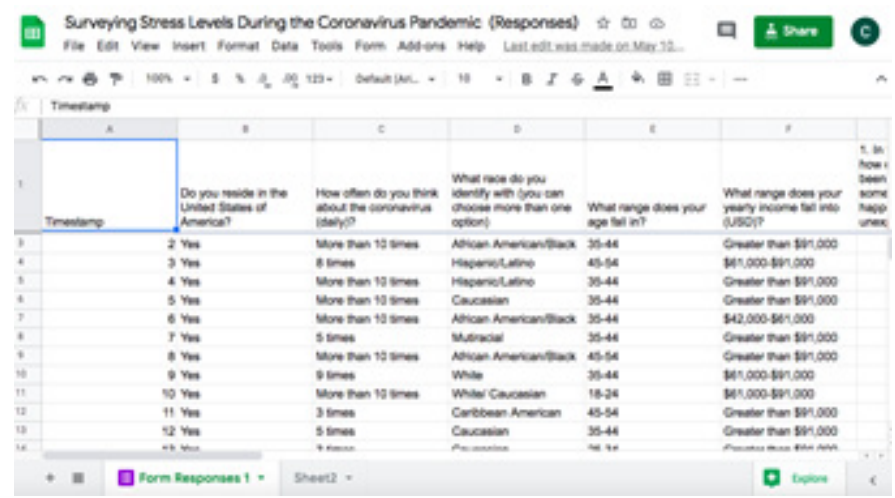

Figure 4. A figure showing the Google Sheets platform that was used to organize data for this study.

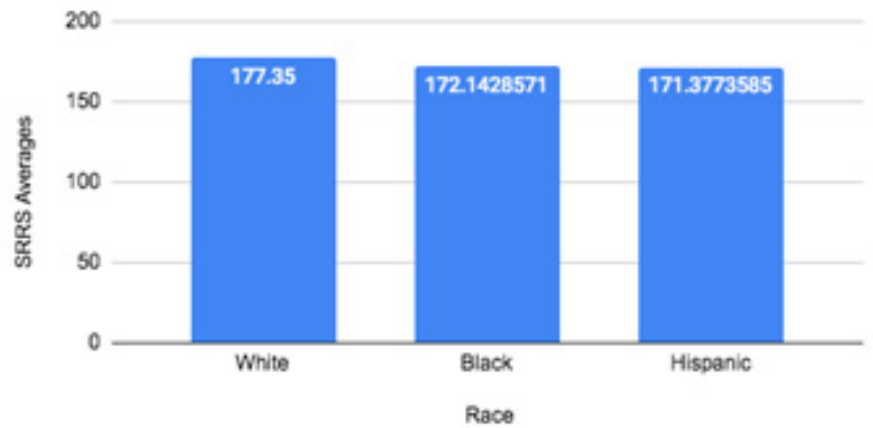

Figure 5. A figure showing the differences in SRRS score between the different Races (White $n=79$; Black $n=132$, Hispanic/Latino $\mathrm{n}=52$ ). 


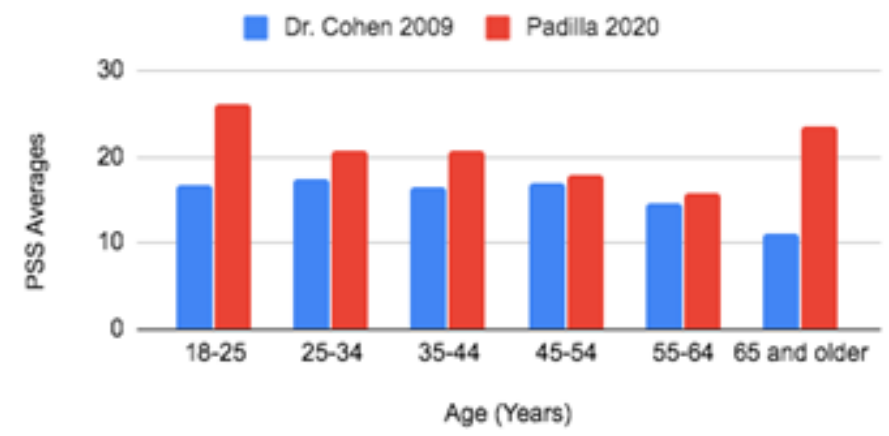

Figure 6. A figure showing the increase in PSS scores between the different Age Groups.

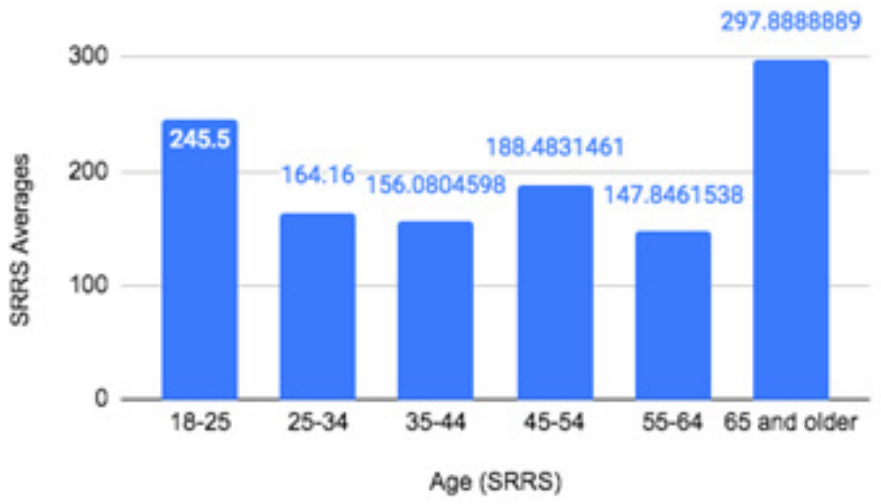

Figure 7. A figure comparing the different average SRRS scores of each age group (18-25 $n=22,25-34 n=51,35-44$ $\mathrm{n}=90,45-54 \mathrm{n}=88,55-64 \mathrm{n}=39,65$ and older $\mathrm{n}=10$ ).

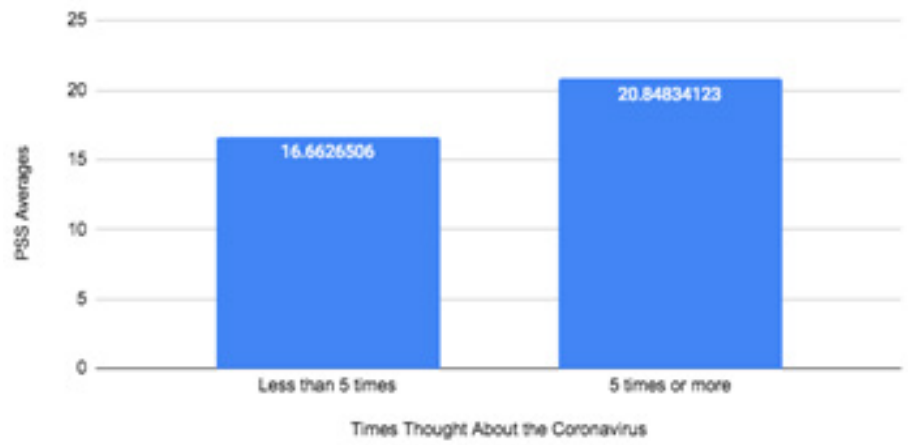

Figure 8. A figure comparing the different PSS scores of people who think about the Coronavirus less than 5 times a day and people who think about the Coronavirus 5 and more times a day. 


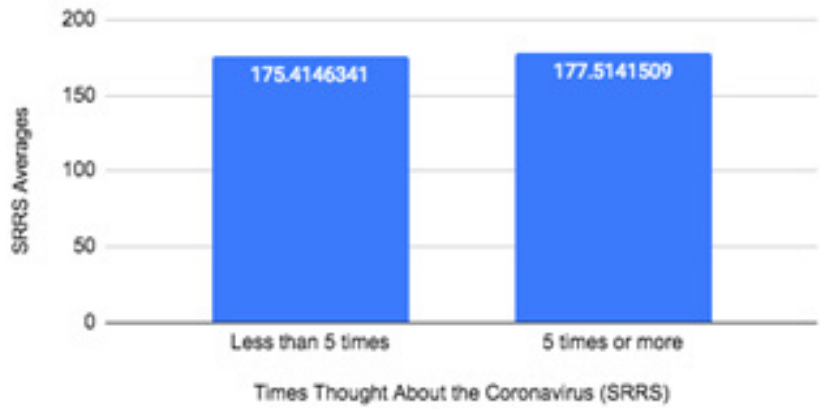

Figure 9. A figure comparing the different SRRS scores of people who think about the Coronavirus less than 5 times a day and people who think about the Coronavirus 5 and more times a day.

\section{Acknowledgment}

I would like to thank Ms. Elaine Pan for helping me with this project.

\section{References}

2020 Poverty Guidelines: ASPE. [Updated 2020 January 21; Accessed 2020 April 2020] https://aspe.hhs.gov/2020poverty-guidelines

Casarella, J. Common Causes of Stress \& Their Effect on Your Health. [Updated ,2020 Mar 09, Accessed April 18] https://www.webmd.com/balance/gui de/causes-of-stress\#1

Cohen Janicki-Deverts 2012. Who's Stressed? Distributions of Psychological Stress in the United States in Probability Samples from 1983, 2006, and 2009:Journal of Applied Social Psychology.[Updated 2012; Accessed 2020 April 18]

https://www.cmu.edu/dietrich/psychology/s tress-immunity-disease-lab/abstracts/pdf/whos stressed jasp 2012.pdf

CPI Inflation Calculator: U.S. Bureau of Labor Statistics. [Accessed 2020 April 19] bin/cpicalc.pl? cost $1=75000 \&$ year $1=200901 \&$ year $2=202003$

Employment Situation News Release: U.S. Bureau of Labor Statistics.[Updated,2020 Apr.03, Accessed 2020 Apr 18] https://www.bls.gov/news.release /empsit.htm

Good Stress, Bad Stress: ULifeline. [Accessed 2020 Apr 18]

http://www.ulifeline.org/articles/450-good-stress-bad-stress

Holmes- Rahe Stress Inventory: The American Institute of Stress.[Updated 2019

April, 10; Accessed 2020 April 20]https://www.stress.org/holmes-rahe-s tress-inventory

Lost your job? Here's how you can cope with it: The Economic Times. [Updated 2017 July 11; Accessed 2020 April 18] https://economictimes.indiatimes.c om/magazines/panache/lost-your-jobhere's-how-you-can-cope-with-i t/articleshow/59540064.cms?from=mdr. 
Perceived Stress Scale Tip Sheet: Emu.edu. [Accessed 2020 April 18] Https:/uwm.edu/mcwp/wp-content/uploads/sites/337/2016/01/Perceived-Stress-Scale-Tip-Sheet.pdf

Shwartz N. 'Nowhere to Hide' as Unemployment Permeates the Economy: The New York Times.[Updated 2020 April 16; Accessed 2020 April 18]https://www.nytimes.c om/2020/04/16/business/economy/unemp loyment-numbers-coronavirus.html

Stress and Life Events: SRRS - Stressful Life Events and Daily Hassles | Simply Psychology [Updated 1970, January 01; Accessed 2020 April, 20] https://www.simplypsychology.org/SRRS.html

Stress: Signs, Symptoms, Management \& Prevention: Cleveland Clinic. [Updated, 2015 Feb 5; Accessed, 2020 Apr 18]https://my.clevelandclinic.org/healt h/articles/ 11874-stress

Stress Symptoms: Physical Effects of Stress on the Body: WebMD.[Updated, 2019 Apr. 01, Accessed 2020, Apr18]http://www.webmd.com/balance/stress-m management/stress-symptoms-effects of-stress-on-the-body\#1.

Simms M., Fortuny K., Henderson H.(2009).Racial and Ethinic Disparities among Low-Income Families: The Urban Institute. [Updated 2009, August; Accessed 2020 April 19] https://www.urban.org/sites/default/fil es/publication/32976/411936-racial-and-ethnic-disparities-among-low-income-families.pdf

Taylor K. The Black Plague: The New Yorker. [Updated 2020 April 16; Accessed 2020 April 19] https://www.newyorker.com/news/our-columnists/t he-black-plague

Taylor C. Influence of perceived threat of Covid-19 and HEXACO personality traits on toilet paper stockpiling;CNBC. [Updated 2020 March 11; Accessed 2020 April 21] https://www.cnbc.com/2020/03/11/heres- why-people-are-panic-buying-and-stockpiling-toilet-paper.html

The Perceived Stress Scale and HPA Assessment: Biohealthlab. [Accessed 2020 April 18] https://www.biohealthlab.com/pss-hpa-assessment.pdf

Wolfe J. African Americans more likely to die from coronavirus illness, early data shows: Reuters. [Updated 2020 April 6; Accessed 2020 April 19] https://www.reuters.com/article/us-health-coronavirus-usa-race/african-americansmore-likely-to-die-from-coronavirus-illness-early-data-shows-idUSKBN21O2B6

Parker K.,Horowitz J., Brown A. About Half of Lower-Income Americans Report Household Job or Wage Loss Due to COVID-19:Pew Research Center. [Updated 2020, April 21; Accessed 19,May] https://www.pewsocialtrends.org/2020/04/21/about-half-of-lower-income-americans-report-household-job-or-wageloss-due-to-covid-19/

Mckay D. Coping With Jop Loss: The Balance Careers. [Updated 2018, 29 Oct; Accessed 2020 19, May] https://www.thebalancecareers.com/coping-

with-job-loss-525766

Lubrano A. High-income Philadelphians getting tested for coronavirus at far higher rates than low-income residents: The Philadelphia Inquirer. [Updated 2020 6, April; Accessed 2020 19, May] https://www.inqui rer.com/news/philadelphia/coronavirus-testing-inequality-poverty-philadelphia-health-insurance20200406.html 
Britt R. Here's Who's Dying From Covid-19 in the United States: Elemental Medium. [ Accessed 2020 19, May]https:/elemental.medium.com/its- not-just-sick-old-people-who-die-from-covid-19-bc9251989bc8

Begley S. What explains Covid-19's lethality for the elderly? Scientists look to 'twilight' of the immune system: Stat news. [Updated 2020, 30 March, Accessed 19 May] https://www.statnews.com/2020/03/30/what-explai ns-coronavirus-lethality-for-elderly/

Sheikh K. Natural Disasters Take a Toll on Mental Health:BrainFacts.org.[Updated 2018, 29 June; Accessed 2020, 19 May]https://www.brai nfacts.org/diseases-and-disorders/mental-health/2018/natural-disasters-take-a-toll-on-mental-health-062818

Mayo Clinic. Meditation: A simple, fast way to reduce stress: Mayo Clinic.[Updated 2020, 20 April; Accessed 2020, 19, May]https: //www.mayoclinic.org/tests-procedures/meditation/in-depth/meditation/art-20045858

Stress by generations: American Psychological Association. [Updated 2012; Accessed 2020 May 1] https://www.apa.org/news/press/releases/stress/2012/generations

Newton R. African Americans and Latinos are more likely to be at risk for depression than Whites: National Institutes of Health. [Updated 2018, May 24; Accessed 2020 May 1] https://www.nih.gov/news-events/n ews-releases/african-americans-latinos-are-more-likely-be-risk-depression-whites Aubrey A. Who's Hit Hardest By COVID-19? Why Obesity, Stress And Race All Matter: NPR Syracuse University. [Updated 2020 April 18; Accessed 2020 May 1]

Assari S. Black Americans may be more resilient to stress than white Americans: Institute for Healthcare and Policy Innovation. [Updated 2016, Sep 16;Accessed 2020 May 1] https://ihpi.umich.edu/news/blac k-americans-may-bemore-resilient-stress-white-americans

Wan W. The coronavirus pandemic is pushing America into a mental health crisis: The Washington Post [Updated 2020 May 5; Accessed 2020 May 1] https://www.washingtonpost.com/health/2020/05/04/mental-hea lth-coronavirus/

Linetti L.Why social media is boosting your stress: The Jakarta Post. [Updated 2019, Jan 9; Accessed 2020 May 1] https://www.thejakartapost.com/ life/2019/01/09/why-social-media-is-boosting-your-stress.html

Hillard J. New Research Shows Social Media Stress Can Lead to Social Media Addiction: Addiction Center. [Updated 2019, Sep 11;Accessed 2020 May 1] https://www.addictioncenter.com/news/2019/09/social-media-stress/

Reynolds D. 'Minority Stress' Is Causing More Men to Live Shorter Lives: Healthline.[Updated 2018, Sep 6;Accessed 2020 May 1] https://www .healthline.com/health-news/minority-stress\#1

The \#1 Reason You Are Stressed and How to Change It: Center for CreativeLeadership.org. [Accessed 2020 May 1] https://www.ccl.org/articles/leading-effectively-articles/banish-stress-stop-ruminating/ 